Article

\title{
Structure of the ALS Mutation Target Annexin A11 Reveals a Stabilising N-Terminal Segment
}

\author{
Peder A. G. Lillebostad ${ }^{1,+}{ }^{+}$Arne Raasakka ${ }^{1,+}{ }^{+}$, Silje J. Hjellbrekke ${ }^{1}$, Sudarshan Patil ${ }^{1}$, \\ Trude Røstbø ${ }^{1}$, Hanne Hollås ${ }^{1}$, Siri A. Sakya ${ }^{1}$, Peter D. Szigetvari ${ }^{1}$, Anni Vedeler ${ }^{1, *}$ and \\ Petri Kursula 1,2,*(D) \\ 1 Department of Biomedicine, University of Bergen, Jonas Lies vei 91, 5009 Bergen, Norway; \\ plillebostad@gmail.com (P.A.G.L.); arne.raasakka@uib.no (A.R.); silje_johj@hotmail.com (S.J.H.); \\ sudarshan.patil@uib.no (S.P.); trude.kr@gmail.com (T.R.); hanhol1404@gmail.com (H.H.); \\ siriasakya@gmail.com (S.A.S.); peter.szigetvari@uib.no (P.D.S.) \\ 2 Faculty of Biochemistry and Molecular Medicine \& Biocenter Oulu, University of Oulu, Aapistie 7, \\ 90220 Oulu, Finland \\ * $\quad$ Correspondence: anni.vedeler@uib.no (A.V.); petri.kursula@uib.no (P.K.); Tel.: +47-55586438 (P.K.) \\ + These authors contributed equally.
}

Received: 27 March 2020; Accepted: 22 April 2020; Published: 24 April 2020

\begin{abstract}
The functions of the annexin family of proteins involve binding to $\mathrm{Ca}^{2+}$, lipid membranes, other proteins, and RNA, and the annexins share a common folded core structure at the $\mathrm{C}$ terminus. Annexin A11 (AnxA11) has a long N-terminal region, which is predicted to be disordered, binds RNA, and forms membraneless organelles involved in neuronal transport. Mutations in AnxA11 have been linked to amyotrophic lateral sclerosis (ALS). We studied the structure and stability of AnxA11 and identified a short stabilising segment in the N-terminal end of the folded core, which links domains I and IV. The crystal structure of the AnxA11 core highlights main-chain hydrogen bonding interactions formed through this bridging segment, which are likely conserved in most annexins. The structure was also used to study the currently known ALS mutations in AnxA11. Three of these mutations correspond to buried Arg residues highly conserved in the annexin family, indicating central roles in annexin folding. The structural data provide starting points for detailed structure-function studies of both full-length AnxA11 and the disease variants being identified in ALS.
\end{abstract}

Keywords: annexin A11; crystal structure; solution structure; calcium binding; membrane binding; protein stability; folding; amyotrophic lateral sclerosis

\section{Introduction}

The annexin (Anx) family of $\mathrm{Ca}^{2+}$-binding proteins is widely distributed in eukaryotes, with twelve Anxs found in vertebrates [1-3]. All Anxs share multiple structural elements, most notably an evolutionarily conserved C-terminal Anx core. This core consists of four similar domains, each comprised of $\sim 70$ amino acids arranged into five $\alpha$ helices, termed A-E [1,4]. The only exception is AnxA6, which contains eight domains, most likely due to a fusion of duplicated anxA5 and anxA10 genes [5]. The five helices within each domain are connected via short loops, forming a right-handed superhelix. Helices A and B as well as helices D and E are oriented pairwise in an antiparallel fashion, while helix $C$ is positioned as a bridge orthogonally to the others [4]. The loops connecting helix $A$ to helix $\mathrm{B}$ and helix $\mathrm{D}$ to helix E contain the $\mathrm{Ca}^{2+}$ binding sites $[1,6]$.

The Anxs are structurally distinct from the EF-hand and C2-domain $\mathrm{Ca}^{2+}$-binding proteins [2]. They reversibly bind negatively charged lipids in a $\mathrm{Ca}^{2+}$-dependent manner, which is a defining feature of this protein family [1]. The binding is mediated through the convex side of the core structure, 
coupled to a conformational change induced by $\mathrm{Ca}^{2+}$ binding [1,2]. Through lipid binding, Anxs can affect important proteolipid membrane properties, such as curvature and phase separation $[7,8]$.

While the folded C-terminal core structure of the vertebrate Anxs is conserved, the structure of the $\mathrm{N}$ terminus varies greatly between different Anxs and determines their individual properties [1]. This region typically contains 10-30 residues, but AnxA7 and AnxA11 harbour unusually long $\mathrm{N}$ termini. AnxA11 has the longest $\mathrm{N}$-terminal domain of all Anxs, with $\sim 200$ residues [9]. The $\mathrm{N}$ termini of AnxA7 and AnxA11 resemble each other, both being hydrophobic, enriched in Gly, Tyr, and Pro [10-12]. The $\mathrm{Ca}^{2+}$-dependent interaction of AnxA11 with phosphatidylserine changes the conformation of its $\mathrm{N}$ terminus [13]. Furthermore, the AnxA11 $\mathrm{N}$ terminus interacts with the apoptosis-linked gene-2 protein (ALG-2) [14] and S100A6 (calcyclin) [15].

Rabbit AnxA11 appears to exist as two isoforms; AnxA11A and AnxA11B [16]. Only the former binds S100A6 in the presence of $\mathrm{Ca}^{2+}$ via the region Gln49-Thr62. This region is absent in AnxA11B [16-18], suggesting isoform-specific functions. S100A6 binds to AnxA1 and AnxA2 in addition to AnxA11 [19,20], indicating functional overlap between these three proteins. According to the UniProt database [21], human AnxA11 is predicted to have two isoforms due to alternative splicing (UniProt ID P50995), leading to a truncation of 33 residues in the $\mathrm{N}$ terminus of the shorter form, while rat AnxA11 only exists as a single isoform corresponding to the longer human isoform (UniProt ID Q5XI77).

In certain cell types, AnxA11 is predominantly localised in the cytoplasm, while in others, it is mainly present in the nucleus $[15,22]$. It is likely that the A isoform is enriched in the nucleus, whereas the $B$ isoform is specifically localised to the cytoplasm [16]. The $\mathrm{N}$ terminus was suggested to be responsible for the nuclear localisation [18,23]. In the nucleus, AnxA11 appears to be involved in events related to the cell cycle. It participates in cytokinesis, playing an essential role in the formation of the midbody. Cells lacking AnxA11 cannot complete cytokinesis and undergo apoptosis [24].

Expression levels of AnxA11 have been linked to various cancers [25-30]. Recent studies have revealed that mutations in AnxA11 play an important role in the development of the neurodegenerative disease amyotrophic lateral sclerosis (ALS) [8,31-37]. The molecular basis of these mutations is unclear, as an experimentally determined 3D structure of AnxA11 has been lacking.

Since the long $\mathrm{N}$ terminus of AnxA11 renders recombinant production of the protein challenging, $\mathrm{N}$-terminally truncated recombinant forms were generated, and the crystal structure of one form, $\triangle 188$ AnxA11, was determined. We show that a 4-residue sequence motif in the $\mathrm{N}$ terminus of the core structure, conserved in most Anxs, functions as a Velcro-like bridging segment and is important for the thermal stability of the Anx core structure. The currently known ALS mutations are analysed based on the crystal structure, providing a view into conserved features of the Anx core fold.

\section{Materials and Methods}

\subsection{Cloning of Full-Length and N-Terminally Truncated Forms of AnxA11}

In order to obtain full-length rat AnxA11, reverse transcriptase-polymerase chain reaction (RT-PCR) was performed using total RNA isolated from PC12 cells by the Trizol method [38]. The cDNA of AnxA11 was obtained using the iScript kit (Bio-Rad, Hercules, CA, USA) according to the manufacturer's instructions and the forward primer $5^{\prime}$-ATCCGG CCATGGGTATGAGCTATCCAGGCTATCCAC-3' (NcoI restriction site is underlined) and the reverse primer 5'-ATCCGGGGTACCTCAGTCGTTGCCACCACAGATC-3' (Acc65I restriction site is underlined). The anxA11 cDNA was digested with $\mathrm{NcoI}$ and Acc65I, purified after separation in a $1 \%$ agarose gel, and ligated into the same restriction sites of the pETM10 vector (a kind gift from Gunter Stier, Heidelberg). Two truncated versions of AnxA11 were generated by PCR using the pETM10 plasmid harbouring rat full-length $a n x \mathrm{~A} 11 \mathrm{cDNA}$ as a template and using the same reverse primer as for full-length AnxA11. The forward primers were 5'-ATCCGGCCATGGGTAGAGGCACCATCA-3' and $5^{\prime}$-ATCCGGCCATGGGTACCGATGCTTCTG-3' (the NcoI restriction site is underlined), resulting 
in $\Delta 188$ AnxA11 (starting with 189-RGTI) and $\Delta 192$ AnxA11 (starting with 193-TDAS), respectively. Both constructs code for the tag sequence MLHHHHHHPMG at the N terminus. The cDNAs were ligated into the pETM10 vector after digestion of PCR fragments with Acc65I and NcoI. Constructs were verified by DNA sequencing.

\subsection{Expression and Purification of Full-Length and N-Terminally Truncated Forms of AnxA11}

E. coli BL21(DE3) cells were transformed with AnxA11 expression plasmids. The bacteria were grown in $5 \mathrm{~mL}$ lysogeny broth (LB) medium with $50 \mu \mathrm{g} / \mathrm{mL}$ kanamycin until an $\mathrm{OD}_{600}$ of 0.6 , after which $1 \mathrm{mM}$ isopropyl $\beta$-D-1-thiogalactopyranoside (IPTG) was added to induce protein expression at $+25{ }^{\circ} \mathrm{C}$ for $4 \mathrm{~h}$ or at $+15{ }^{\circ} \mathrm{C}$ overnight $(\mathrm{ON})$, to determine optimal expression conditions. At the end of protein expression, $1 \mathrm{~mL}$ of the culture was withdrawn and centrifuged at $2000 \times g$ for $10 \mathrm{~min}$ at $+4{ }^{\circ} \mathrm{C}$. The supernatant was discarded, and the pellet was resuspended in $500 \mu \mathrm{L}$ lysis buffer $\left(50 \mathrm{mM} \mathrm{Na}_{2} \mathrm{HPO}_{4}, 500 \mathrm{mM} \mathrm{NaCl}, 5 \%\right.$ (v/v) glycerol, $10 \mathrm{mM}$ imidazole) containing $0.5 \mu \mathrm{g} / \mathrm{mL}$ DNase I (Sigma, St. Louis, MO, USA), $0.25 \mu \mathrm{g} / \mathrm{mL}$ RNase A (Sigma, St. Louis, MO, USA), and cOmplete EDTA-free protease inhibitor cocktail (Roche, Basel, Switzerland). The samples were sonicated on ice, whereafter $100-\mu \mathrm{L}$ aliquots (total lysate) were withdrawn. Additional $100-\mu \mathrm{L}$ aliquots of the lysates were transferred into new tubes and centrifuged at $21,000 \times g$ for $15 \mathrm{~min}$ at $+4{ }^{\circ} \mathrm{C}$. The supernatant was withdrawn. The pellet was resuspended in $100 \mu \mathrm{L}$ lysis buffer. After addition of denaturation buffer, $20 \mu \mathrm{L}$ of the protein samples were separated on 4-20\% SDS-PAGE (Mini-PROTEAN TGX Precast Protein Gels, Bio-Rad, Hercules, CA, USA) at $20 \mathrm{~mA}$ and $250 \mathrm{~V}$ as the limiting voltage.

For large-scale purification, the above procedure was repeated using $300 \mathrm{~mL}$ LB medium. The full-length (FL) and N-terminally truncated AnxA11 were induced at $+25{ }^{\circ} \mathrm{C}$ for $4 \mathrm{~h}$, while FL-AnxA11 was also expressed $\mathrm{ON}$ at $+15^{\circ} \mathrm{C}$. The cells were collected by centrifugation at $4000 \times g$ for $15 \mathrm{~min}$. The pellets were frozen at $-80^{\circ} \mathrm{C}$ in lysis buffer before the addition of $0.5 \mu \mathrm{g} / \mathrm{mL}$ DNase I, $0.25 \mu \mathrm{g} / \mathrm{mL}$ RNase A, and cOmplete EDTA-free protease inhibitor cocktail (Roche, Basel, Switzerland). Subsequently, cells were broken by sonication, and the lysates were centrifuged at $16,000 \times g$ for $30 \mathrm{~min}$ at $+4{ }^{\circ} \mathrm{C}$. All purification steps were performed at $+4{ }^{\circ} \mathrm{C}$.

We took advantage of an N-terminal His-tag to purify AnxA11, which reduces degradation at the $\mathrm{N}$ terminus [13]. Purification using $\mathrm{Co}^{2+}-\mathrm{NTA}$ gave higher yields than $\mathrm{Ni}^{2+}-\mathrm{NTA}$ resin. The lysate supernatant was loaded onto a $\mathrm{Co}^{2+}$-NTA agarose column and incubated for 30 min with gentle rotation. Subsequently, the proteins on the $\mathrm{Co}^{2+}$ resin were washed with equilibration buffer $(50 \mathrm{mM}$ $\mathrm{Na}_{2} \mathrm{HPO}_{4}, 0.3 \mathrm{M} \mathrm{NaCl}, 10 \mathrm{mM}$ imidazole; $\mathrm{pH}$ 8) and high-salt buffer (50 mM Na $2 \mathrm{HPO}_{4}, 1 \mathrm{M} \mathrm{NaCl}$, $10 \mathrm{mM}$ imidazole; $\mathrm{pH}$ 8), both buffers containing EDTA-free protease inhibitors. Elution buffer (50 mM $\mathrm{Na}_{2} \mathrm{HPO}_{4}, 0.3 \mathrm{M} \mathrm{NaCl}, 250 \mathrm{mM}$ imidazole; $\mathrm{pH}$ 8) containing EDTA-free protease inhibitors was used to elute the proteins. After adding EGTA to a final concentration of $2 \mathrm{mM}$, the eluates were quickly transferred onto PD-10 columns for a buffer exchange to $20 \mathrm{mM}$ Tris ( $\mathrm{pH} 8$ ). All recombinant forms of AnxA11 were subjected to size exclusion chromatography using a Superdex 75 or 200 Increase 10/300 GL column (GE Healthcare, Chicago, IL, USA). Protein concentration was determined by absorbance at $280 \mathrm{~nm}$ (using molecular masses of 55513, 36828, and $36401 \mathrm{Da}$ and sequence-based extinction coefficients of 42750,13410 , and $13410 \mathrm{M}^{-1} \mathrm{~cm}^{-1}$ for full-length AnxA11, $\Delta 188 \mathrm{AnxA} 11$, and $\triangle 192 A n x A 11$, respectively). The protein size and purity were confirmed by SDS-PAGE and Coomassie Brilliant Blue staining.

\subsection{Circular Dichroism Spectroscopy}

A Jasco J-810 spectropolarimeter (Jasco, Hampshire, UK) with a Peltier temperature control unit was used for far-UV circular dichroism (CD) spectroscopy. Melting curves were recorded from +25 to $+75^{\circ} \mathrm{C}$ at $222 \mathrm{~nm}$, at a heating rate of $40{ }^{\circ} \mathrm{C} / \mathrm{h}$, to determine the thermal transition temperature $\left(\mathrm{T}_{\mathrm{m}}\right) . \mathrm{T}_{\mathrm{m}}$ was estimated in GraphPad Prism 7 (GraphPad, San Diego, CA, USA) using four-parameter logistic regression. 
Synchrotron radiation CD (SRCD) data were acquired from $0.5 \mathrm{mg} / \mathrm{mL} \triangle 188 \mathrm{AnxA11}$ and $\triangle 192 \mathrm{AnxA11}$ in $20 \mathrm{mM}$ Tris-HCl, pH 8.0, on the AU-CD synchrotron beamline at ASTRID2 (ISA, Aarhus, Denmark). Samples containing $1 \mathrm{mM} \mathrm{CaCl}_{2}$ were included in addition to $\mathrm{CaCl}_{2}$-free samples to detect $\mathrm{Ca}^{2+}$-induced changes in the secondary structure content. Closed $100-\mu \mathrm{M}$ circular cells were used (Suprasil, Hellma Analytics, Müllheim, Germany). Spectra were recorded from 170 to $280 \mathrm{~nm}$ at $+10^{\circ} \mathrm{C}$. Baselines were subtracted, and CD units were converted to $\Delta \varepsilon\left(\mathrm{M}^{-1} \mathrm{~cm}^{-1}\right)$ in CDtoolX 1.06 [39]. The spectra were truncated based on the HT voltage and the CD spectrum noise levels.

\subsection{Small-Angle X-Ray Scattering}

SAXS data were collected from $0.41-2.96 \mathrm{mg} / \mathrm{mL} \Delta 188 \mathrm{AnxA11}$ and $\Delta 192 \mathrm{AnxA} 11$ in $20 \mathrm{mM}$ Tris-HCl on the EMBL/DESY P12 beamline, PETRA III (Hamburg, Germany) [40] (Figure S1). Protein samples at $0.7-1.0 \mathrm{mg} / \mathrm{mL}$ were then studied with $0-1 \mathrm{mM} \mathrm{CaCl}_{2}$ to follow potential oligomerisation. Monomeric bovine serum albumin $(66.5 \mathrm{kDa})$ was used as a molecular weight standard. Data were processed and analysed using the ATSAS package 2.8.4 [41], and GNOM 5.0 was used to calculate distance distribution functions [42]. Theoretical scattering of the crystal structure was calculated and fitted against the SAXS data using CRYSOL 2.8.3 [43]. Ab initio modelling was performed using GASBOR 2.3i [44]. SUPCOMB 2.3 [45] was used for crystal structure and ab initio model superposition. SAXS data collection, processing, and fitting parameters are presented in Table 1.

Table 1. Small-angle X-ray scattering parameters and analysis.

\begin{tabular}{|c|c|c|}
\hline \multicolumn{3}{|c|}{ Data Collection Parameters } \\
\hline Instrument & \multicolumn{2}{|c|}{ P12, PETRAIII, DESY } \\
\hline Wavelength (nm) & \multicolumn{2}{|c|}{0.124} \\
\hline Angular range $\left(\mathrm{nm}^{-1}\right)$ & \multicolumn{2}{|c|}{$0.022-7.33$} \\
\hline Exposure time (s) & \multicolumn{2}{|c|}{0.045} \\
\hline Exposure temperature $\left({ }^{\circ} \mathrm{C}\right)$ & \multicolumn{2}{|c|}{10} \\
\hline Protein & AnxA11 188 & AnxA11 $\Delta 192$ \\
\hline Concentration range $(\mathrm{mg} / \mathrm{mL})$ & $0.77-2.96$ & $0.41-1.18$ \\
\hline \multicolumn{3}{|c|}{ Structural Parameters } \\
\hline$I_{0}$ (relative) [from Guinier] & 0.02759 & 0.0274 \\
\hline$R_{\mathrm{g}}(\mathrm{nm})[$ from Guinier] & $2.44 \pm 0.13$ & $2.43 \pm 0.20$ \\
\hline$I_{0}$ (relative) $[$ from $\mathrm{P}(\mathrm{r})]$ & 0.02692 & 0.02748 \\
\hline$R_{\mathrm{g}}(\mathrm{nm})[$ from $\mathrm{P}(\mathrm{r})]$ & $2.500 \pm 0.016$ & $2.503 \pm 0.019$ \\
\hline$D_{\max }(\mathrm{nm})[$ from GNOM] & 10.00 & 9.97 \\
\hline$V_{\text {Porod }}\left(\mathrm{nm}^{3}\right)$ [from GNOM] & 58.03 & 59.53 \\
\hline \multicolumn{3}{|c|}{ Molecular Mass Determination } \\
\hline Molecular mass $\mathrm{M}_{\mathrm{r}}(\mathrm{kDa})$ [from $I_{0}$ using Guinier] ${ }^{1}$ & 34.3 & 34.1 \\
\hline Molecular mass $\mathrm{M}_{\mathrm{r}}(\mathrm{kDa})\left[\text { from } I_{0} \text { using } \mathrm{P}(\mathrm{r})\right]^{1}$ & 33.5 & 34.2 \\
\hline Molecular mass $\mathrm{M}_{\mathrm{r}}(\mathrm{kDa})$ [from $\left.\mathrm{V}_{\text {Porod }}\right]$ & 34.1 & 35.0 \\
\hline Molecular mass $\mathrm{M}_{\mathrm{r}}(\mathrm{kDa})$ [from absolute scale] & 34.8 & 34.8 \\
\hline Theoretical $\mathrm{M}_{\mathrm{r}}$ from sequence $(\mathrm{kDa})$ & 36.8 & 36.4 \\
\hline \multicolumn{3}{|c|}{ Software } \\
\hline Primary data reduction \& processing & \\
\hline $\mathrm{Ab}$ initio modelling & \multicolumn{2}{|c|}{ GASBOR } \\
\hline$x^{2}$ & 0.770 & 0.629 \\
\hline Fitting of theoretical scattering curve to data & \multicolumn{2}{|c|}{ CRYSOL } \\
\hline$x^{2}$ & 0.888 & 0.749 \\
\hline
\end{tabular}

${ }^{1}$ Monomeric BSA standard was used as reference $\left(\mathrm{M}_{\mathrm{r}}=66.5 \mathrm{kDa} ; I_{0}=0.0534\right)$. 


\subsection{Protein Crystallisation, Data Collection, and Structure Determination}

Sitting-drop vapour diffusion crystallisation experiments were set up in 96-well format. X-ray diffraction data were collected on the EMBL P13 beamline, PETRA III (Hamburg, Germany) [46] from a crystal grown in $100 \mathrm{mM}$ Bis-tris ( $\mathrm{pH} 5.5$ ), $3 \mathrm{M} \mathrm{NaCl}$ at $+20^{\circ} \mathrm{C}$; the drop contained $150 \mathrm{~nL}$ of $12.7 \mathrm{mg} / \mathrm{mL} \Delta 188 \mathrm{AnxA} 11$ and $150 \mathrm{~nL}$ of reservoir solution. The crystal was cryoprotected by adding a solution containing $25 \%$ glycerol and $75 \%$ reservoir solution directly onto the crystallisation drop. Upon mounting, the crystal was flash-frozen in liquid $\mathrm{N}_{2}$, and it was kept at $100 \mathrm{~K}$ during X-ray diffraction data collection.

Diffraction data were processed with XDS [47], and the structure was solved by molecular replacement in Phaser 2.8.3 [48] with PDB entry 1ANN (bovine AnxA4) as a search model [49]. Refinement was carried out using phenix.refine 1.18 [50], and model building with coot 0.8.9.1 [51]. The structure quality was assessed with MolProbity [52]. The data processing and refinement statistics are presented in Table 2.

Table 2. Crystallographic data collection and refinement.

\begin{tabular}{|c|c|}
\hline \multicolumn{2}{|c|}{ Data Collection } \\
\hline Construct & $\Delta 188 \mathrm{AnxA11}$ \\
\hline Wavelength $(\AA)$ & 0.9763 \\
\hline Space group & $\mathrm{P} 1$ \\
\hline Unit cell parameters & $\begin{array}{l}a=39.1 \AA, b=86.7 \AA, c=87.3 \AA \\
\alpha=114.0^{\circ}, \beta=102.0^{\circ}, \gamma=97.2^{\circ}\end{array}$ \\
\hline Resolution range $(\AA)$ & $50-2.30(2.36-2.30)^{1}$ \\
\hline Completeness (\%) & $95.4(95.0)$ \\
\hline Reflections total/unique & $141110 / 42245(9818 / 3046)$ \\
\hline$\langle\mathrm{I} / \sigma \mathrm{I}\rangle$ & $5.2(1.1)$ \\
\hline $\mathrm{R}_{\text {sym }}(\%)$ & $17.5(164.0)$ \\
\hline$R_{\text {meas }}(\%)$ & $20.9(196.6)$ \\
\hline $\mathrm{CC}_{1 / 2}(\%)$ & $99.2(47.6)$ \\
\hline redundancy & $3.3(3.2)$ \\
\hline \multicolumn{2}{|c|}{ Data Processing } \\
\hline $\mathrm{R}_{\text {cryst }} / \mathrm{R}_{\text {free }}(\%)$ & $22.8(26.6)$ \\
\hline Rmsd bond length $(\AA)$ & 0.002 \\
\hline Rmsd bond angle $\left(^{\circ}\right)$ & 0.4 \\
\hline MolProbity score (percentile) & 1.58 (98th) \\
\hline $\begin{array}{c}\text { Ramachandran } \\
\text { favoured/disallowed (\%) }\end{array}$ & $97.2 / 0.3$ \\
\hline
\end{tabular}

${ }^{1}$ Numbers in parentheses refer to the highest-resolution shell.

For structure analysis, the programs PyMOL 2.3.2 [53] and its APBS [54] plugin were used. The refined AnxA11 crystal structure, along with the experimental structure factors, was deposited at the PDB with the entry code 6TU2.

\section{Results and Discussion}

\subsection{Solubility Assays, Large-Scale Expression, and Purification of the N-Terminally Truncated Forms of AnxA11}

We studied recombinant rat AnxA11, which is nearly identical to the human AnxA11 (Figure 1A). Induction was performed at $+25{ }^{\circ} \mathrm{C}$ for $4 \mathrm{~h}$ and at $+15{ }^{\circ} \mathrm{C} \mathrm{ON}$ to determine optimal expression conditions. There was little or no difference in yield between the two modes of expression. FL-AnxA11 was consistently more challenging to express than its truncated forms, yielding remarkably low concentrations, and it was notoriously prone to aggregation, as reported previously [13]. The solubility of the truncated forms of AnxA11 in bacterial lysates was assessed after centrifugation at 21,000 $\mathrm{g}$ 
by comparing samples from the total bacterial lysate with the corresponding supernatant and pellet by SDS-PAGE (Figure 1B). Two N-terminally truncated versions of AnxA11 were designed, cloned, expressed, and purified, namely, $\Delta 188$ AnxA11 and $\Delta 192 A n x A 11$. Previously, we noticed by sequence alignment that a segment of $\sim 10$ residues in the $\mathrm{N}$ terminus preceding the first $\alpha$ helix of domain $\mathrm{I}$ is highly conserved in Anxs [55]. In addition, the N-terminal residues that immediately precede the core domain have been suggested to stabilise the overall structure of AnxA2 [55,56].
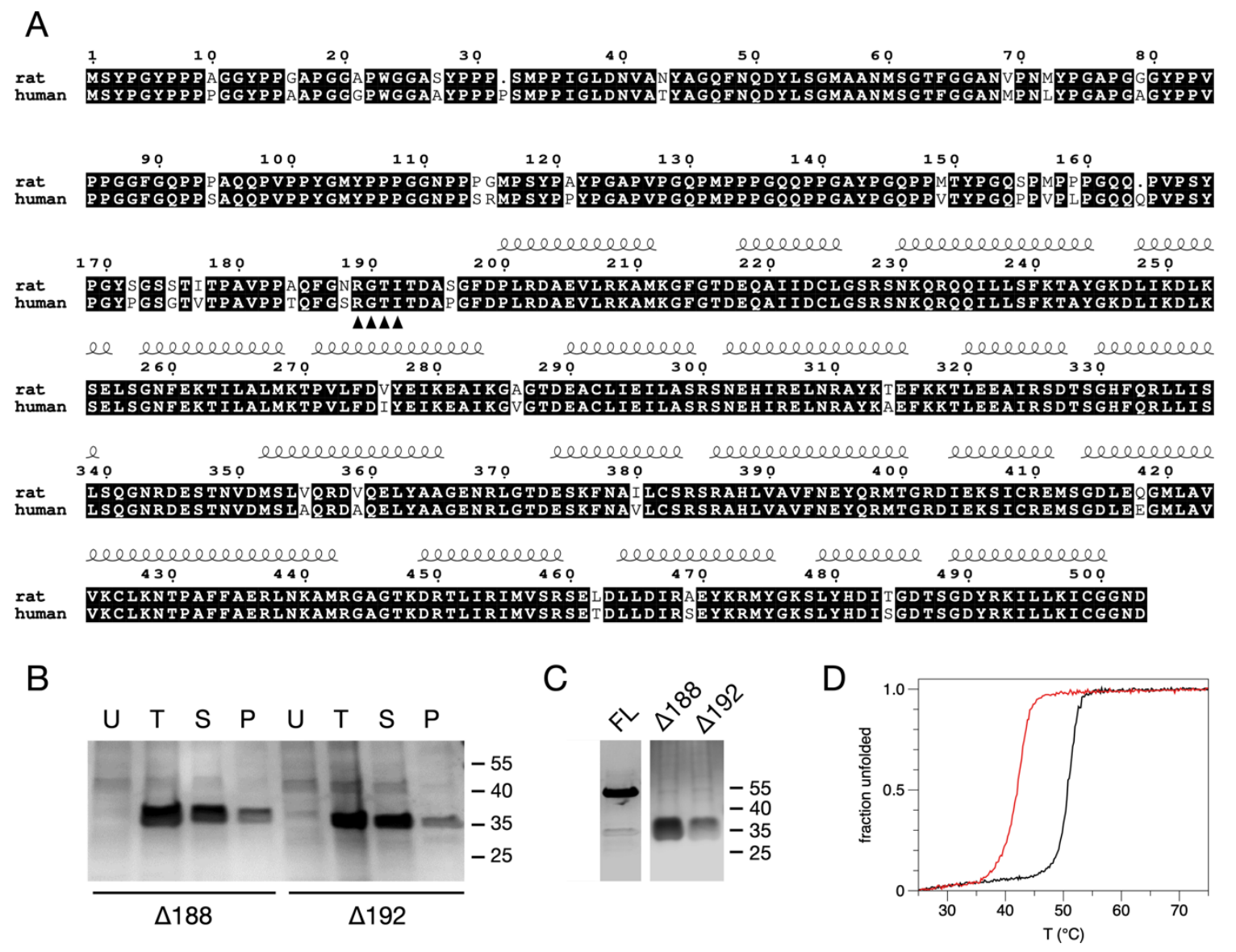

Figure 1. The solubility, purification, and stability of N-terminally truncated forms of rat AnxA11. (A) Sequence alignment between rat and human AnxA11. (B) Uninduced (U), total (T), supernatant (S), and pellet (P) fractions of bacterial lysates containing $\triangle 188 \mathrm{AnxA} 11$ or $\Delta 192 \mathrm{AnxA11}$ as indicated. (C) $10 \mu \mathrm{L}$ of FL-AnxA11 and the N-terminally truncated forms $\Delta 188$ AnxA11 and $\Delta 192$ AnxA11, purified using $\mathrm{Co}^{2+}$-resin. Molecular mass standards are indicated to the right. Proteins were separated in $10 \%$ SDS-PAGE gels and Coomassie-stained. (D) CD-monitored thermal disruption of $\alpha$-helicity of $20 \mu \mathrm{M}$ $\Delta 188$ AnxA11 (black) and $\Delta 192$ AnxA11 (red).

In contrast to FL-AnxA11, both $\Delta 188$ AnxA11 and $\Delta 192 A n x A 11$ were mainly soluble (Figure 1B). FL-AnxA11 as well as the N-terminally truncated $\Delta 188$ AnxA11 and $\Delta 192$ AnxA11 were purified by affinity chromatography on $\mathrm{Co}^{2+}$-resin, which greatly improved the purity of the recombinant proteins compared to $\mathrm{Ni}^{2+}$-based chromatography. The $\mathrm{N}$-terminal truncations resulted in a marked enhancement in expression, giving a five-to-tenfold increase in yield compared to FL-AnxA11 (Figure 1C). This suggests that the $\mathrm{N}$ terminus is responsible for the aggregation of the full-length protein. This may be related to the observed phase separation phenomena linked to the N-terminal segment [8] or misfolding of the protein in bacterial cells. 


\subsection{Thermal Stability of the N-Terminally Truncated $\Delta 188 A n x A 11$ and $\Delta 192 A n x A 11$}

To address thermal stability, ellipticity at $222 \mathrm{~nm}$ was monitored as a function of temperature for $\Delta 188 \mathrm{AnxA} 11$ and $\Delta 192 \mathrm{AnxA} 11$. The thermal transition temperatures were estimated from the inflection points of the melting curves (Figure 1D). The $T_{m}$ of FL-AnxA11 was earlier reported to be $+45^{\circ} \mathrm{C}$ [13]. The $\mathrm{T}_{\mathrm{m}}$ of $\Delta 188 \mathrm{AnxA} 11$ showed a $\mathrm{T}_{\mathrm{m}}$ of $+50.76 \pm 0.02{ }^{\circ} \mathrm{C}$, while that of $\Delta 192 \mathrm{AnxA} 11$ was substantially lower $\left(+41.87 \pm 0.02{ }^{\circ} \mathrm{C}\right)$. This difference highlights the importance of the four amino acid residues 189-RGTI-192 in thermally stabilising the core structure of AnxA11. Cooperative unfolding of the two truncated forms of AnxA11 remained largely unchanged but decreased slightly in $\Delta 192 A n x A 11$. This increased thermal stability of $\Delta 188$ AnxA11 compared to $\Delta 192 A n x A 11$ may explain why we obtained crystals of $\Delta 188$ AnxA11, but not of the other $\mathrm{N}$-terminally truncated form. The dramatic difference in $\mathrm{T}_{\mathrm{m}}$ is necessarily accounted for by at least one of the four additional residues present in $\Delta 188$ AnxA11 being involved in the stabilising of the core structure.

\subsection{The Crystal Structure of AnxA11}

Using $\Delta 188$ AnxA11, we solved the crystal structure of the rat AnxA11 core domain. The asymmetric unit contains three molecules of AnxA11, and the structure presents the canonical Anx core fold. The $\mathrm{Ca}^{2+}$ binding sites are partially occupied, whereby two monomers have three $\mathrm{Ca}^{2+}$ ions bound, and one monomer has four (Figure 2). As is typical for the Anxs, all $\mathrm{Ca}^{2+}$ binding sites are on one face of the molecule, promoting calcium-dependent lipid membrane binding (Figure 2).
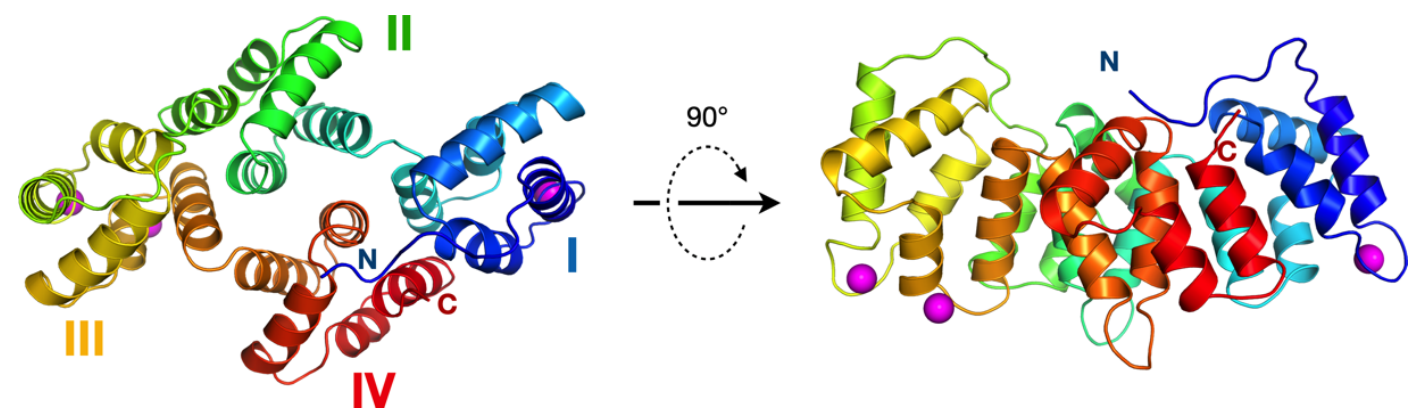

Figure 2. Crystal structure of the AnxA11 core domain. The four subdomains are numbered and coloured from blue to red. The $\mathrm{N}$ and $\mathrm{C}$ termini are indicated, and bound $\mathrm{Ca}^{2+}$ ions are shown in magenta. Shown is one monomer of the three in the asymmetric unit.

The substantial difference in thermal stability induced by the four N-terminal residues of the $\Delta 188$ AnxA11 construct implies an important structural element at this position. This segment, $\sim 10$ residues before the AnxA11 domain I helix A, is central in the folded structure, making interactions with the termini of several helices of the Anx fold, and effectively enabling a tight contact between the $\mathrm{N}$ terminus of domain I and the $\mathrm{C}$ terminus of domain IV (Figure $3 \mathrm{~A}, \mathrm{~B}$ ). 
A

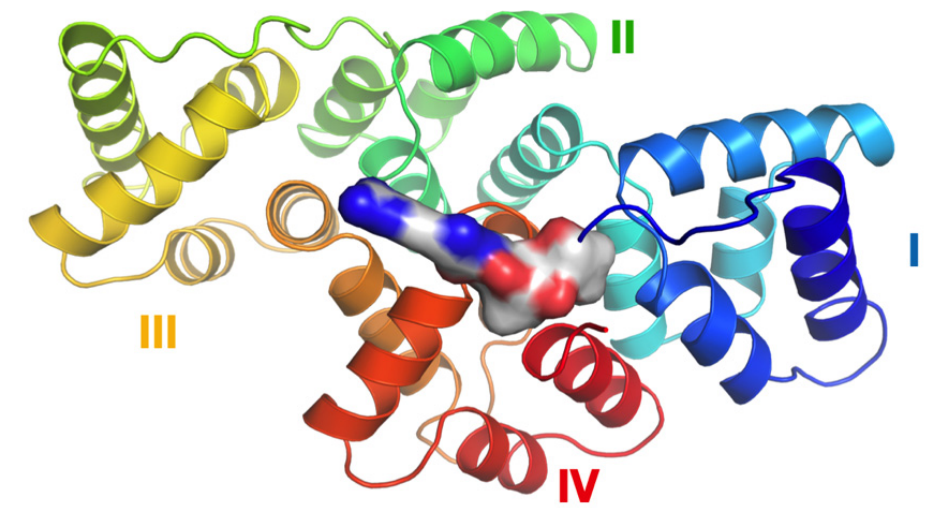

B
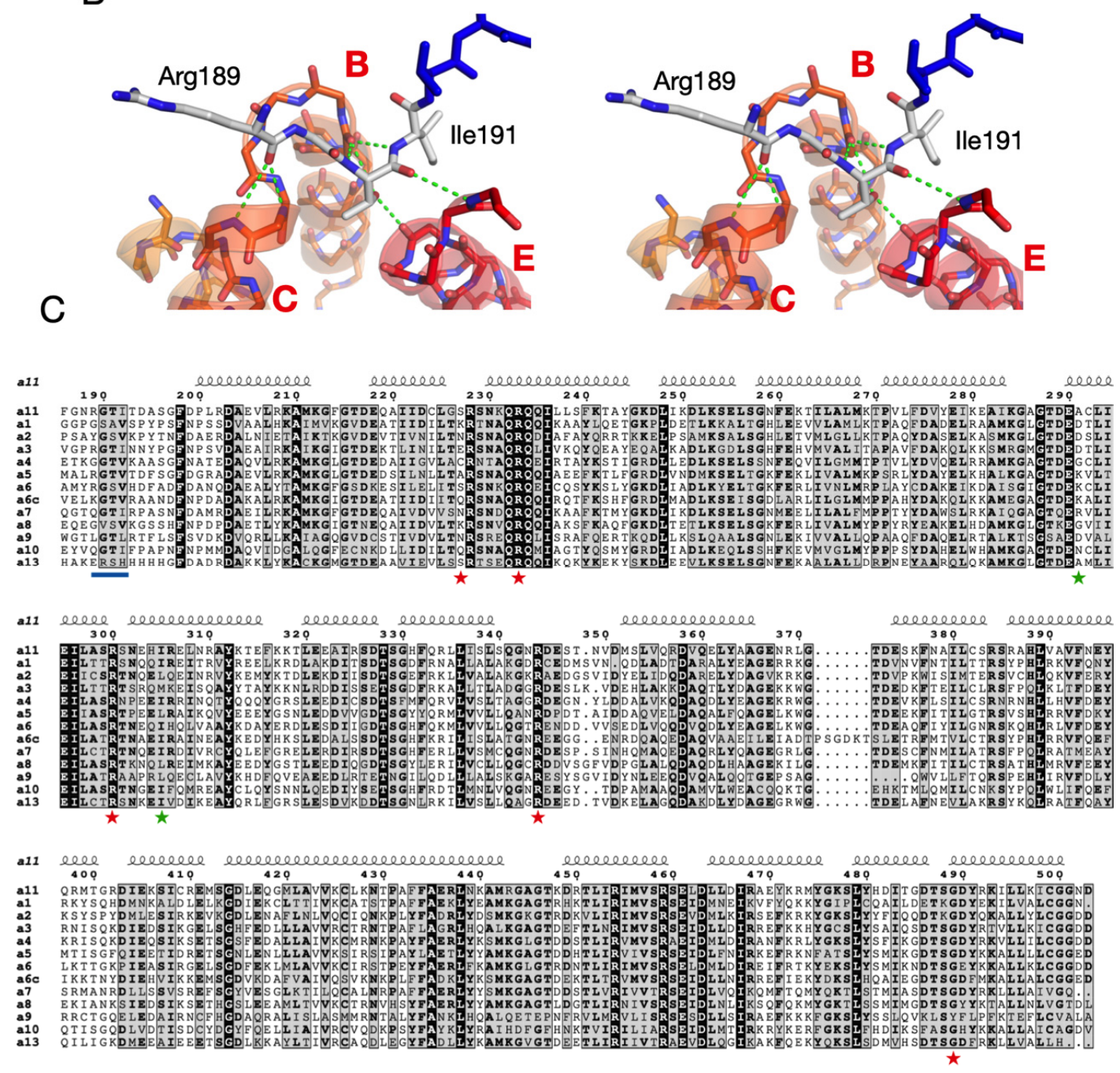

Figure 3. Rat annexins and conservation of the RGTI motif. (A) The N-terminal Velcro-like bridging segment is shown in surface mode, bound to domain IV. (B) Stereo view of the hydrogen bonding interactions of the motif with three helices in domain IV. (C) Sequence alignment of all rat Anxs. The N-terminal motif is underlined in blue, and the mutations (red) and variants (green) linked to ALS are shown with asterisks. A6 and A6c correspond to the N- and C-terminal halves of AnxA6.

Comparisons with other Anxs show that the segment 189-192 is a conserved motif in the Anx family. The only Anx that does not contain the motif at the sequence level is AnxA13; conservation is weak for AnxA1 and AnxA8. The 4-residue segment forms conserved interactions with the ends of 
helices in domain IV (Figure 3B). These interactions are mainly comprised of main-chain hydrogen bonds, which explains the mode of conservation and the importance of the Gly residue in the motif. Interestingly, it has been proposed that AnxA11 is the common ancestor of all mammalian Anxs [57], except for AnxA7 and AnxA13 - the two phylogenetically oldest Anxs [58]. Thus, the AnxA11 core domain has the highest similarity to the other mammalian Anxs, acting as a sort of prototype [59].

The PhosphoSite database lists a number of phosphorylation sites for Anxs, most of which come from high-throughput assays [60]. AnxA11 is phosphorylated, but the exact sites remain unknown [15]. Interestingly, the well-characterised Tyr23 and Ser25 phosphorylation sites of AnxA2 lie within the 4-residue bridging region (Figure 3C). Phosphorylation at Tyr23 and Ser25 results in a closed or open conformation, respectively, of AnxA2 [56]. Similarly, a phosphomimicking mutation in Thr6 of AnxA4 results in an opening of the structure [61], hinting at a general mechanism of Anx conformation regulation through phosphorylation of the RGTI motif. A comparison of the structures of AnxA11, AnxA2, and AnxA4 is presented in Figure 4. Of other Anxs, AnxA6 has a phosphorylation site in the bridging segment [62]. These findings can be understood based on the conserved structure of the observed bridging segment. The regulation of this segment through post-translational modification may be a general means to regulate overall conformation and dynamics of Anxs, possibly resulting in altered binding to functional ligands, such as RNA or membranes.
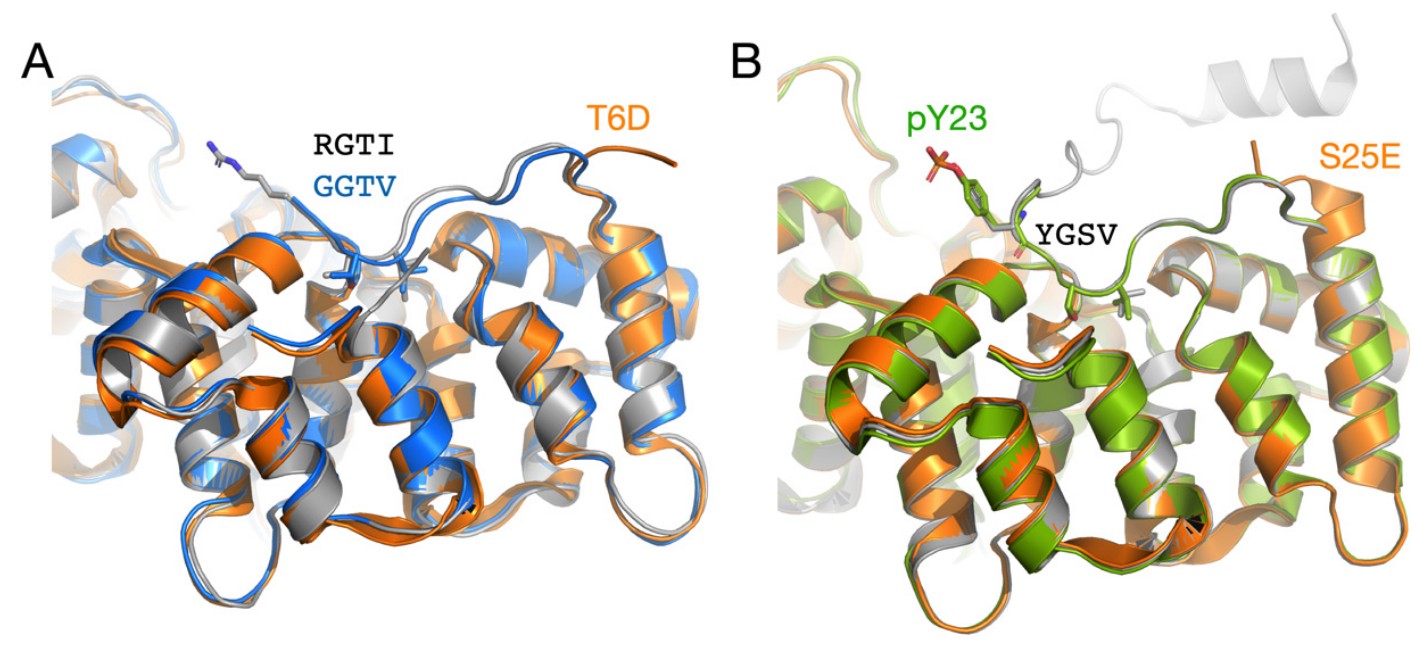

Figure 4. Regulation of the RGTI motif via phosphorylation in other annexins. (A) Comparison of AnxA11 (grey) with AnxA4 (blue) [49]. The structure of the phosphomimicking AnxA4 T6D mutant [61] is shown in orange and has an open conformation. (B) Three states of AnxA2 [56]. The nonphosphorylated protein is in grey, AnxA2 phosphorylated on Tyr23 in green, and the open conformation of S25E in orange.

The crystal structure of AnxA11 presents trimers very similar to those formed by AnxA5 (Figure 5), and hence, could be expected to interact with membranes in a similar manner. In the crystal, the trimers are arranged in layers, with similar contacts as observed for AnxA4 and AnxA5 between the trimers. Similarly to other Anx assemblies, the $\mathrm{Ca}^{2+}$ binding sites of the AnxA11 trimer are all on the same face, which would be in direct contact with the membrane (Figure 5A). The membrane-facing surface in the trimer gains a positive charge potential upon $\mathrm{Ca}^{2+}$ binding, while the opposite side is relatively featureless (Figure 5B). This observation further highlights the common function of the Anx core structure in binding membrane surfaces, while the N-terminal domain is responsible for most functional differences between the Anxs [1]. AnxA5 has been the most studied Anx on membrane surfaces, on which it forms a crystal-like lattice of trimers [63-66]. The trimer arrangement of AnxA11 in the crystal closely resembles that of AnxA5 in crystals and on membranes (Figure 5C,D) [63-66]. Notably, similarly to AnxA11, AnxA4 and AnxA5 are monomeric in solution [67-69]. 

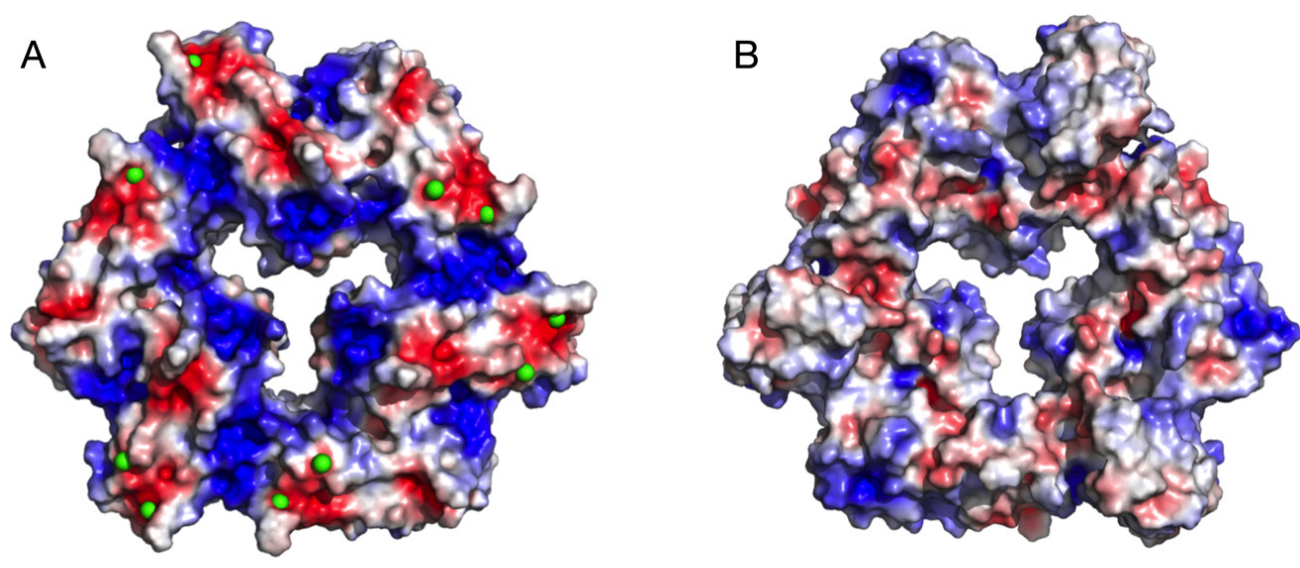

$-5$

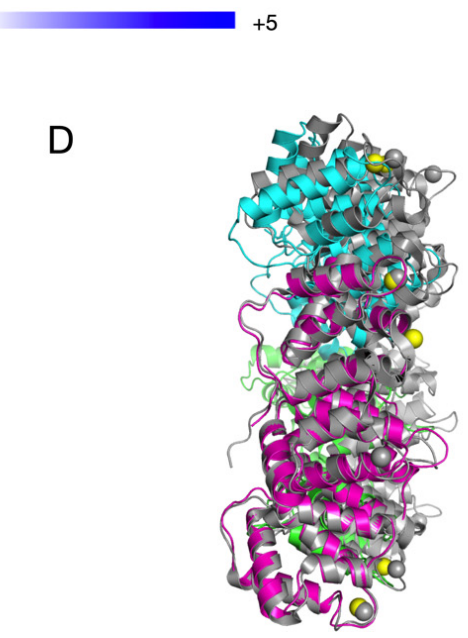

C

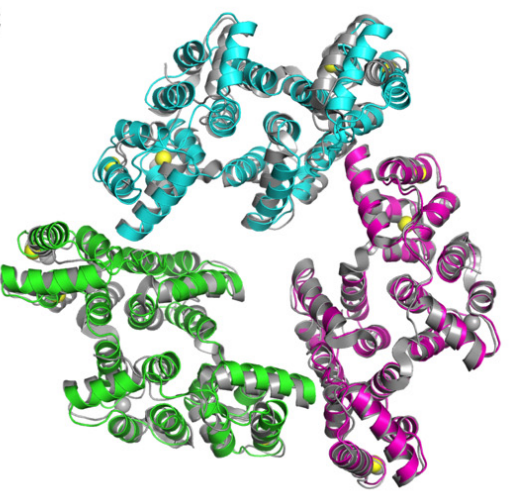

Figure 5. Trimeric assembly of AnxA11 in the crystal. (A) AnxA11 trimer surface coloured with electrostatic potential. The view from the $\mathrm{Ca}^{2+}$-binding face. $\mathrm{Ca}^{2+}$ ions are shown as green spheres. The negative sites (red) are the locations for $\mathrm{Ca}^{2+}$ binding, and their neutralization will make the surface very positive, enabling lipid membrane binding. (B) The opposite face of AnxA11 is relatively featureless. (C) Superposition of AnxA11 (coloured) with the AnxA5 trimer (gray) [64]. Superposition was done based on one monomer (bottom right) to better highlight possible differences in assembly. The view is the same as in (B). (D) Side view of the superimposed AnxA11 and AnxA5 trimers.

One might assume that AnxA11 would arrange on a membrane much like it does in the crystal; the N-terminal segments would then point away from the membrane. This is in line with the observations that AnxA11 induces membrane curvature [7], as well as the suggestion that the $\mathrm{N}$ terminus of AnxA11 binds to RNA, while the core structure binds to lipids in lysosomes for long-distance co-transport in neurons [8]. The RNA binding site in AnxA2 has been shown to reside within domain IV [70]. The binding dynamics were recently investigated; AnxA2 binds strongly to an RNA 8-mer (5'-GGGGAUUG-3') with a $\mathrm{K}_{\mathrm{d}}$ of 30 $\mathrm{nM}$ [71]. The RNA binding sites in AnxA11 have not been determined.

\subsection{Structure-Based Analysis of ALS Disease Mutations}

The crystal structure of rat AnxA11 allows one to analyse the structural basis of AnxA11 mutations linked to amyotrophic lateral sclerosis (ALS) [35] in humans. The sequence identity between full-length rat and human AnxA11 is $93.3 \%$, being 96.5\% for the core structure. The identification of AnxA11 as an ALS gene is rather recent, and mutations are being continuously identified. Thus, it is safe to assume that more ALS mutations will be identified in the future. We studied the mutations thus far linked to ALS with respect to potential structural implications. Many of the mutations, including the best-characterised D40G [35], lie in the N-terminal extension, which is not present in the crystallised 
construct. The mutations in this region could affect protein-protein interactions, protein localisation, phase separation, or binding to mRNA [8]. More interesting for the current structural study, however, are the mutations identified within the Anx core domain.

Five mutations have thus far been described in ALS patients within the AnxA11 core: S229R, R235Q, R302C, R346C, and G491R; in addition, G189E is located two residues before the start of the crystallised rat AnxA11 construct [35,37]. In the 3D structure, the AnxA11 mutations can be observed clustered at two locations (Figure 6A). Interestingly, three of these mutations involve a buried Arg residue, and a close look at the alignment reveals that these Arg residues are fully conserved in all rat Anxs. The remaining two mutations replace an exposed, non-conserved, small residue with an Arg. Details of the environment of each of the three conserved Arg residues are shown in Figure 6B-D. In brief, two of them coordinate carbonyl groups at $C$ termini of helices, and one is involved in a conserved extended buried network of salt bridges between domains II and IV. These locations suggest that the ALS mutations involving these conserved Arg residues will have effects on AnxA11 folding and/or stability.

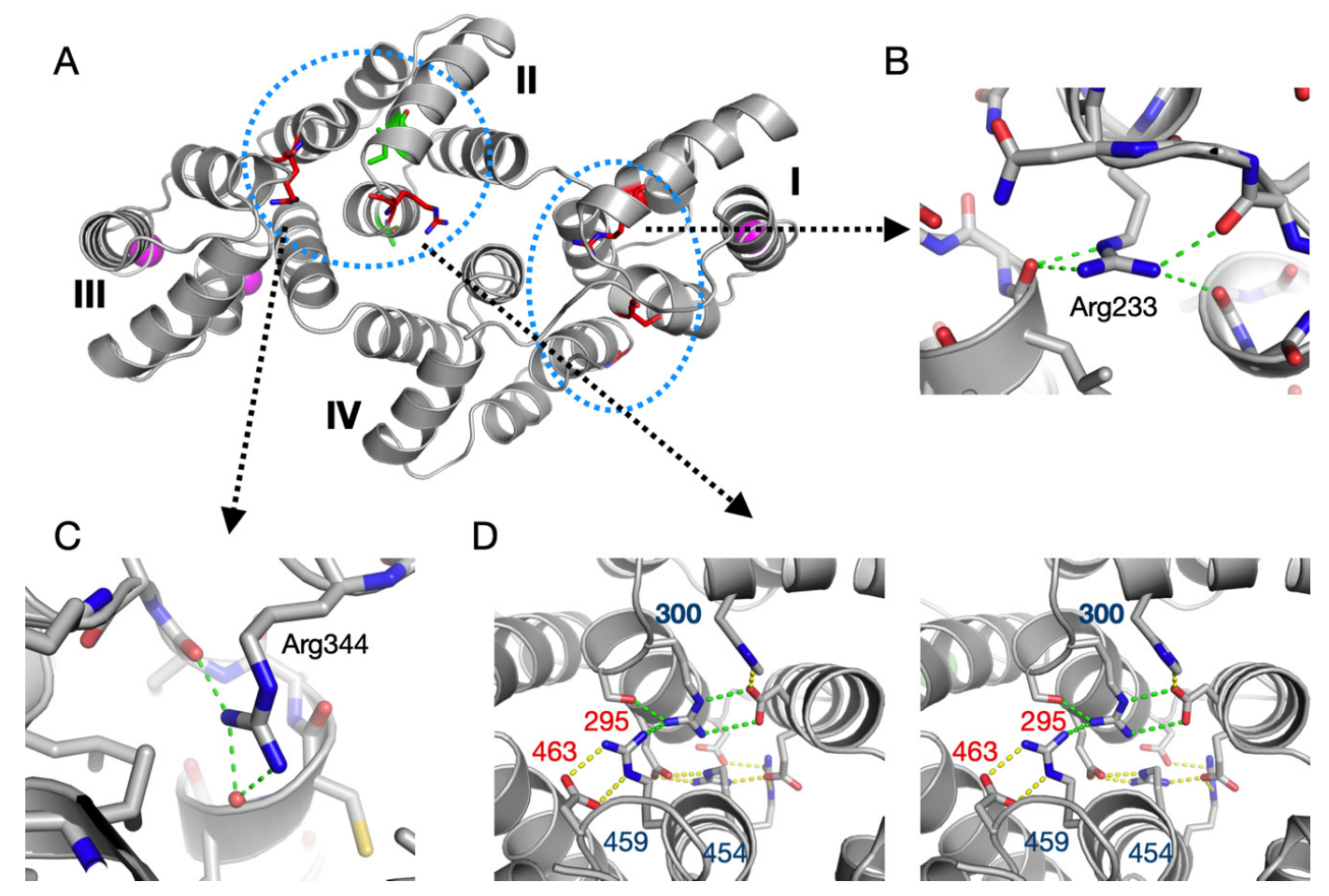

Figure 6. Location of ALS mutations and variants in the AnxA11 structure. (A) The five ALS mutations (see text) are highlighted in red and the two rare variants in green. The two 3D clusters of mutations/variants are shown with blue dashed circles. One cluster lies in domain II, possibly affecting folding and/or interactions with domain III. The other cluster is at the interface between domains I and IV, i.e., the N and C terminus of the AnxA11 core structure. (B) Arg233 (corresponding to the human R235Q mutation) makes four contacts to carbonyl groups at the C-terminal end of domain I helices B and E. With its buried positive charge, Arg233 interacts with the negative helix dipole from both helices. (C) Arg344 (corresponding to R346C) similarly caps helix B of domain III. (D) An extended salt bridge network exists between domains II (top) and IV (bottom) (stereo view). Arg300 (corresponds to R302C) is central in this network. The charged residues with numbers indicated are fully conserved in all rat Anxs (Arg, blue; acidic, red).

$\Delta \Delta \mathrm{G}$ predictions for the five mutations on the SDM server [72] indicate decreased stability for all mutations except S229R. Hence, the affected residues may be important for correct folding and/or stability of AnxA11. Recent functional characterisation of the AnxA11 ALS mutation R235Q shows that the mutant protein is prone to aggregation and sequesters FL-AnxA11. This in turn abolishes the binding to calcyclin [35]. In addition, two rare missense variants, A293V and I307M, were recently discovered in the Chinese Han population [34]. These residues are located in domain II (Figure 6). 
The N-terminal tail of AnxA11 has a unique amino acid composition, reminiscent of disordered proteins able to undergo liquid-liquid phase separation (LLPS) [73]. It has the hallmarks of an extended segment poised for $\pi-\pi$ interactions, which are central in LLPS [74]. Indeed, the AnxA11 N-terminal region was recently shown to promote LLPS; its $\mathrm{N}$ terminus binds to RNA granules, which do not contain membranes, while the core structure binds to lipids in membranes [8]. The effects of this phase separation on the stability of the AnxA11 core domain are currently unknown. Furthermore, ALS-associated mutations in both the $\mathrm{N}$ terminus (D40G) and C terminus (R346C) of AnxA11 were shown to promote phase transition from liquid-liquid droplets to more stable gel-like states within AnxA11 droplets and in addition impair the reversal of the states. As a consequence, these mutations disrupt the function of AnxA11 to tether RNA granules with lysosomes [8].

\subsection{The Solution Behaviour of the AnxA11 Core}

The thermal stability difference between $\Delta 188$ AnxA11 and $\Delta 192$ AnxA11 prompted us to study their conformation in solution using SAXS and SRCD. In SAXS, both variants were monomeric with identical distance distributions and globular folds that superposed well with the crystal structure (Figure 7A-E), indicating that the absence of the RGTI stretch does not lead to large-scale conformational changes. Despite the trimeric packing in the crystal, AnxA11 is monomeric in solution under the employed conditions.
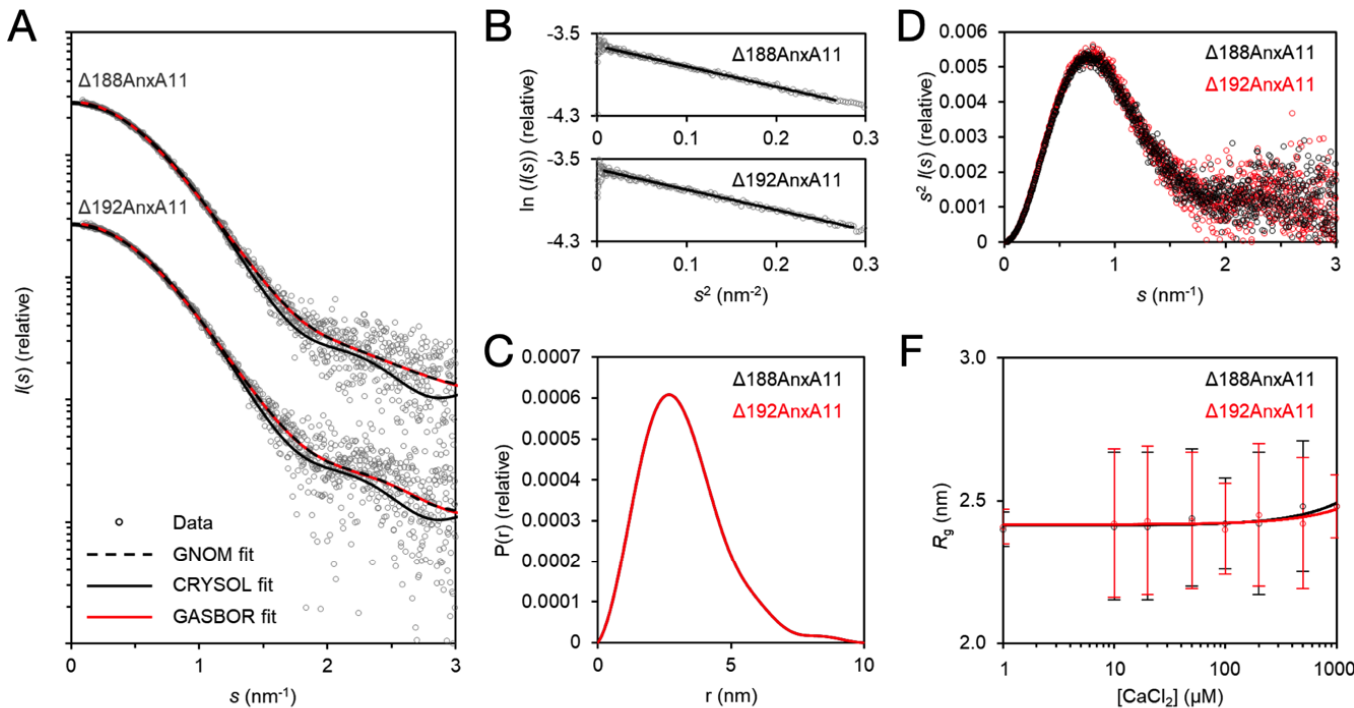

$E$
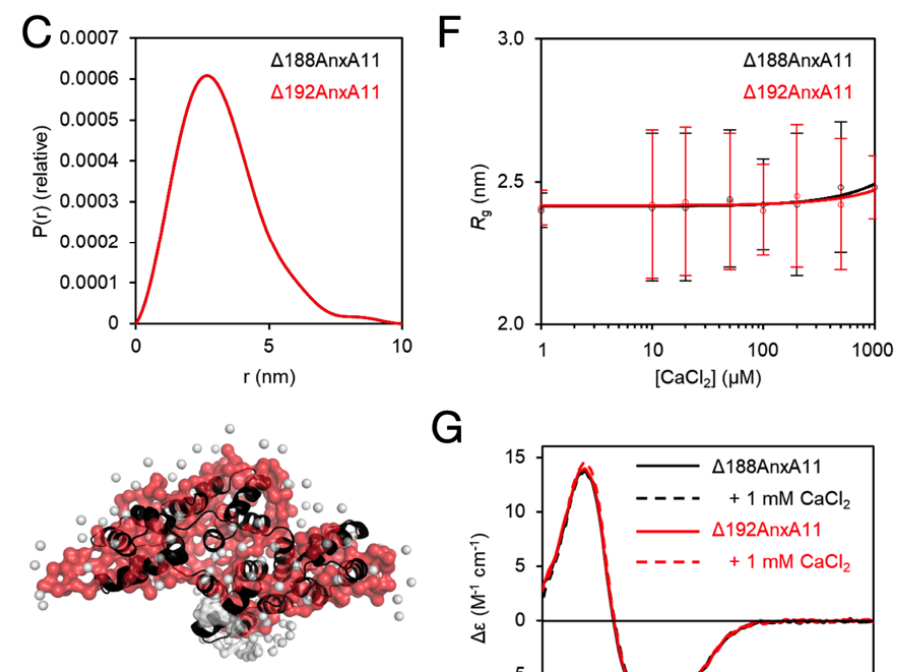

G

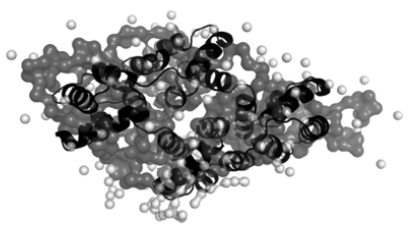

$\triangle 188$ AnxA11

$\chi^{2}{ }_{\text {GASBOR }}=0.770$

$\chi^{2}$ CRYSOL $=0.888$

$\triangle 192 A n x A 11$

$\chi_{\text {GASBOR }}^{2}=0.629$

$\chi^{2}$ CRYSOL $=0.749$

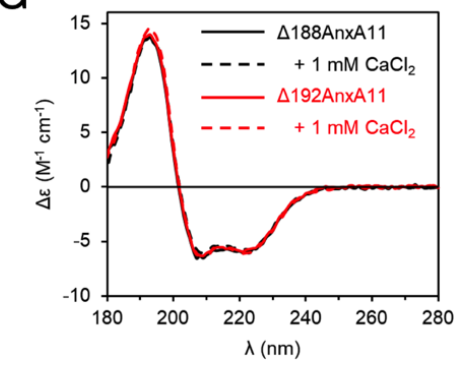

Figure 7. SAXS and SRCD analysis of $\triangle 188 \mathrm{AnxA11}$ and $\triangle 192 \mathrm{AnxA} 11$. (A) SAXS data for $\triangle 188 \mathrm{AnxA} 11$ and $\triangle 192 A n x A 11$ have been offset for clarity. GNOM, GASBOR, and CRYSOL fits are plotted over the measured data to denote the accuracy of distance distribution analysis, ab initio modeling, and theoretical scattering calculated from the crystal structure. (B) Guinier analysis. (C) Distance distribution diagram from GNOM. (D) Kratky plot of the SAXS data. (E) GASBOR ab initio models based on the SAXS data. The crystal structure (black) has been fitted inside. $\chi^{2}$ values of the GASBOR and CRYSOL fits are indicated. (F) $\mathrm{R}_{\mathrm{g}}$ as a function of $\mathrm{CaCl}_{2}$ concentration. The error bars represent the fitting error from Guinier analysis.

(G) SRCD spectra of $\triangle 188 \mathrm{AnxA11}$ and $\Delta 192 \mathrm{AnxA11}$ in the presence and absence of $1 \mathrm{mM} \mathrm{CaCl}$. 
Similarly to most Anxs, AnxA11 has been implicated in $\mathrm{Ca}^{2+}$ binding [1,13]. Structural studies of many Anxs have revealed $\mathrm{Ca}^{2+}$ binding to the convex side of the core structure, essentially through coordination by acidic residues. To test for effect of $\mathrm{Ca}^{2+}$ on the folding of the core structure of AnxA11, we titrated $\triangle 188 \mathrm{AnxA} 11$ and $\triangle 192 \mathrm{AnxA} 11$ with $\mathrm{CaCl}_{2}$ in SAXS and followed the radius of gyration ( $\mathrm{R}_{\mathrm{g}}$; Figure $\left.7 \mathrm{~F}\right)$. The $\mathrm{R}_{\mathrm{g}}$ of both truncated proteins remained the same up to $1 \mathrm{mM} \mathrm{CaCl} 2$. Additionally, we carried out SRCD spectroscopy of $\triangle 188 \mathrm{AnxA11}$ and $\triangle 192 \mathrm{AnxA11}$ in the absence and presence of $1 \mathrm{mM} \mathrm{CaCl}_{2}$ (Figure 7G). The spectral quality was excellent, with the data being truncated at $178 \mathrm{~nm}$. The presence of $\mathrm{Ca}^{2+}$ did not alter the spectra, indicating that $\mathrm{Ca}^{2+}$ does not influence the secondary structure content of the core structure. This result confirms that $\Delta 192 \mathrm{AnxA11}$ is folded despite its dramatic decrease in thermal stability, and that the degree of secondary structure content between the two variants is nearly identical. $\mathrm{Ca}^{2+}$ induced a large thermal stabilisation of FL-AnxA11, indicated by a rise in $\mathrm{T}_{\mathrm{m}}$ of $\sim 14{ }^{\circ} \mathrm{C}$ [13]. The presence of up to $75 \mathrm{mM} \mathrm{Ca}^{2+}$ only induced small increases in AnxA11 $\alpha$-helical content [13]. Thus, $\mathrm{Ca}^{2+}$ binding results in only local conformational changes, which primes AnxA11 for lipid membrane binding.

\section{Conclusions}

As the diversity of the vertebrate Anx family is mainly realised through the uniqueness of the $\mathrm{N}$-terminal tail $[1,16,75,76]$, many functional features are lost by truncation. However, crucial functional properties of interest, such as mRNA binding, $\mathrm{Ca}^{2+}$-dependent binding to phospholipids, as well as $\mathrm{Ca}^{2+}$ binding itself, may be retained. Thus, truncated Anxs may serve as a foundation for functional studies, dodging practical issues often encountered due to their long $\mathrm{N}$ termini.

The crystal structure of AnxA11, although similar to known Anx core domain structures, provides important starting points to further understand the structure-function relationships in AnxA11 and other Anx family members. The identification of a strongly stabilizing Velcro-like bridging segment at the $\mathrm{N}$ terminus of the Anx core, as well as the fact that many known ALS mutations correspond to highly conserved buried Arg residues in the Anx fold, provide new insights into Anx folding. AnxA11, like many other ALS targets, is part of a membraneless organelle, a ribonucleoprotein complex, involved in neuronal transport of mRNA granules [8,77-79]. It is evident that this process can be affected by mutations in either the N-terminal region or the folded core domain of AnxA11, which in turn can affect binding to RNA, lipid membranes, and $\mathrm{Ca}^{2+}$. The fact that the bridging segment is a target for regulatory phosphorylation in AnxA2 shows that in addition to simply stabilizing the core structure, this segment may be a conformational switch common to most Anxs.

Supplementary Materials: The following are available online at http://www.mdpi.com/2218-273X/10/4/660/s1, Figure S1: $\Delta 188$ AnxA11 and $\Delta 192$ AnxA11 SAXS dilution data.

Author Contributions: Conceptualization, A.V. and P.K.; methodology, P.A.G.L., A.R., and A.V.; validation, A.R. and P.K.; formal analysis, A.R. and P.K.; investigation, P.A.G.L., A.R., S.J.H., S.P., T.R., H.H., S.A.S., P.D.S., A.V., and P.K.; resources, P.A.G.L., S.J.H., S.P., T.R., H.H., S.A.S., P.D.S., and A.V.; data curation, A.R. and P.K.; writing-original draft preparation, P.A.G.L., A.R., and A.V.; writing-review and editing, A.R., A.V., and P.K.; visualization, A.R. and P.K.; supervision, A.V. and P.K.; project administration, A.V. and P.K.; funding acquisition, A.V. and P.K. All authors have read and agreed to the published version of the manuscript.

Funding: This research was funded by the University of Bergen. Synchrotron visits were supported by the EU Framework Programme for Research and Innovation HORIZON 2020 iNEXT and CALIPSOplus programmes, grant numbers 653706 and 730872.

Acknowledgments: We thank Marianne Goris for valuable assistance in the laboratory. Crystallographic and SAXS data were collected on EMBL Hamburg beamlines P13 and P12, respectively, at the PETRA III storage ring (DESY, Hamburg, Germany). We are also grateful for the SRCD beamline support at the ASTRID2 synchrotron facility (Aarhus, Denmark). We thank the BiSS facility at the University of Bergen for providing vital instrumentation for this study.

Conflicts of Interest: The authors declare no conflict of interest. 


\section{References}

1. Gerke, V.; Moss, S.E. Annexins: From structure to function. Physiol. Rev. 2002, 82, 331-371. [CrossRef] [PubMed]

2. Gerke, V.; Creutz, C.E.; Moss, S.E. Annexins: Linking Ca2+ signalling to membrane dynamics. Nat. Rev. Mol. Cell Biol. 2005, 6, 449-461. [CrossRef] [PubMed]

3. Moss, S.E.; Morgan, R.O. The annexins. Genome Biol. 2004, 5, 219. [CrossRef]

4. Liemann, S.; Huber, R. Three-dimensional structure of annexins. Cell Mol. Life Sci. 1997, 53, 516-521. [CrossRef] [PubMed]

5. Morgan, R.O.; Jenkins, N.A.; Gilbert, D.J.; Copeland, N.G.; Balsara, B.R.; Testa, J.R.; Fernandez, M.P. Novel human and mouse annexin A10 are linked to the genome duplications during early chordate evolution. Genomics 1999, 60, 40-49. [CrossRef] [PubMed]

6. Rosengarth, A.; Luecke, H. A calcium-driven conformational switch of the N-terminal and core domains of annexin A1. J. Mol. Biol. 2003, 326, 1317-1325. [CrossRef]

7. Boye, T.L.; Jeppesen, J.C.; Maeda, K.; Pezeshkian, W.; Solovyeva, V.; Nylandsted, J.; Simonsen, A.C. Annexins induce curvature on free-edge membranes displaying distinct morphologies. Sci. Rep. 2018, 8, 10309. [CrossRef]

8. Liao, Y.C.; Fernandopulle, M.S.; Wang, G.; Choi, H.; Hao, L.; Drerup, C.M.; Patel, R.; Qamar, S.; Nixon-Abell, J.; Shen, Y.; et al. RNA Granules Hitchhike on Lysosomes for Long-Distance Transport, Using Annexin A11 as a Molecular Tether. Cell 2019, 179, 147-164.e20. [CrossRef]

9. Tokumitsu, H.; Mizutani, A.; Muramatsu, M.; Yokota, T.; Arai, K.; Hidaka, H. Molecular cloning of rabbit CAP-50, a calcyclin-associated annexin protein. Biochem. Biophys. Res. Commun. 1992, 186, 1227-1235. [CrossRef]

10. Burns, A.L.; Magendzo, K.; Shirvan, A.; Srivastava, M.; Rojas, E.; Alijani, M.R.; Pollard, H.B. Calcium channel activity of purified human synexin and structure of the human synexin gene. Proc. Natl. Acad. Sci. USA 1989, 86, 3798-3802. [CrossRef]

11. Creutz, C.E.; Snyder, S.L.; Husted, L.D.; Beggerly, L.K.; Fox, J.W. Pattern of repeating aromatic residues in synexin. Similarity to the cytoplasmic domain of synaptophysin. Biochem. Biophys. Res. Commun. 1988, 152, 1298-1303. [CrossRef]

12. Creutz, C.E. Novel protein ligands of the annexin A7 N-terminal region suggest pro-beta helices engage one another with high specificity. Gen. Physiol. Biophys. 2009, 28, F7-F13.

13. Lecona, E.; Turnay, J.; Olmo, N.; Guzman-Aranguez, A.; Morgan, R.O.; Fernandez, M.P.; Lizarbe, M.A. Structural and functional characterization of recombinant mouse annexin A11: Influence of calcium binding. Biochem. J. 2003, 373, 437-449. [CrossRef] [PubMed]

14. Satoh, H.; Shibata, H.; Nakano, Y.; Kitaura, Y.; Maki, M. ALG-2 interacts with the amino-terminal domain of annexin XI in a Ca(2+)-dependent manner. Biochem. Biophys. Res. Commun. 2002, 291, 1166-1172. [CrossRef] [PubMed]

15. Mizutani, A.; Tokumitsu, H.; Kobayashi, R.; Hidaka, H. Phosphorylation of annexin XI (CAP-50) in SR-3Y1 cells. J. Biol. Chem. 1993, 268, 15517-15522.

16. Sudo, T.; Hidaka, H. Regulation of calcyclin (S100A6) binding by alternative splicing in the N-terminal regulatory domain of annexin XI isoforms. J. Biol. Chem. 1998, 273, 6351-6357. [CrossRef]

17. Tokumitsu, H.; Mizutani, A.; Hidaka, H. Calcyclin-binding site located on the NH2-terminal domain of rabbit CAP-50 (annexin XI): Functional expression of CAP-50 in Escherichia coli. Arch. Biochem. Biophys. 1993, 303, 302-306. [CrossRef]

18. Tomas, A.; Moss, S.E. Calcium- and cell cycle-dependent association of annexin 11 with the nuclear envelope. J. Biol. Chem. 2003, 278, 20210-20216. [CrossRef]

19. Naka, M.; Qing, Z.X.; Sasaki, T.; Kise,H.; Tawara, I.; Hamaguchi, S.; Tanaka, T. Purification and characterization of a novel calcium-binding protein, S100C, from porcine heart. Biochim. Biophys. Acta 1994, 1223, 348-353. [CrossRef]

20. Powell, M.A.; Glenney, J.R. Regulation of calpactin I phospholipid binding by calpactin I light-chain binding and phosphorylation by p60v-src. Biochem. J. 1987, 247, 321-328. [CrossRef]

21. Consortium, T.U. UniProt: A worldwide hub of protein knowledge. Nucleic Acids Res. 2019, 47, D506-D515. [CrossRef] [PubMed] 
22. Mizutani, A.; Usuda, N.; Tokumitsu, H.; Minami, H.; Yasui, K.; Kobayashi, R.; Hidaka, H. CAP-50, a newly identified annexin, localizes in nuclei of cultured fibroblast 3Y1 cells. J. Biol. Chem. 1992, 267, 13498-13504. [PubMed]

23. Mizutani, A.; Watanabe, N.; Kitao, T.; Tokumitsu, H.; Hidaka, H. The long amino-terminal tail domain of annexin XI is necessary for its nuclear localization. Arch. Biochem. Biophys. 1995, 318, 157-165. [CrossRef] [PubMed]

24. Tomas, A.; Futter, C.; Moss, S.E. Annexin 11 is required for midbody formation and completion of the terminal phase of cytokinesis. J. Cell Biol. 2004, 165, 813-822. [CrossRef] [PubMed]

25. Duncan, R.; Carpenter, B.; Main, L.C.; Telfer, C.; Murray, G.I. Characterisation and protein expression profiling of annexins in colorectal cancer. Br. J. Cancer 2008, 98, 426-433. [CrossRef]

26. Fernandez-Madrid, F.; Tang, N.; Alansari, H.; Granda, J.L.; Tait, L.; Amirikia, K.C.; Moroianu, M.; Wang, X.; Karvonen, R.L. Autoantibodies to Annexin XI-A and Other Autoantigens in the Diagnosis of Breast Cancer. Cancer Res. 2004, 64, 5089-5096. [CrossRef]

27. Hua, K.; Li, Y.; Zhao, Q.; Fan, L.; Tan, B.; Gu, J. Downregulation of Annexin A11 (ANXA11) Inhibits Cell Proliferation, Invasion, and Migration via the AKT/GSK-3beta Pathway in Gastric Cancer. Med. Sci. Monit. 2018, 24, 149-160. [CrossRef]

28. Song, J.; Shih Ie, M.; Chan, D.W.; Zhang, Z. Suppression of annexin A11 in ovarian cancer: Implications in chemoresistance. Neoplasia 2009, 11, 605-614, 1 p following 614. [CrossRef]

29. Wang, J.; Guo, C.; Liu, S.; Qi, H.; Yin, Y.; Liang, R.; Sun, M.Z.; Greenaway, F.T. Annexin A11 in disease. Clin. Chim. Acta 2014, 431, 164-168. [CrossRef]

30. Xin, W.; Rhodes, D.R.; Ingold, C.; Chinnaiyan, A.M.; Rubin, M.A. Dysregulation of the annexin family protein family is associated with prostate cancer progression. Am. J. Pathol. 2003, 162, 255-261. [CrossRef]

31. Brenner, D.; Weishaupt, J.H. Update on amyotrophic lateral sclerosis genetics. Curr. Opin. Neurol. 2019, 32, 735-739. [CrossRef]

32. Fernandopulle, M.; Wang, G.; Nixon-Abell, J.; Qamar, S.; Balaji, V.; Morihara, R.; St George-Hyslop, P.H. Inherited and Sporadic Amyotrophic Lateral Sclerosis and Fronto-Temporal Lobar Degenerations arising from Pathological Condensates of Phase Separating Proteins. Hum. Mol. Genet. 2019, 28, R187-R196. [CrossRef] [PubMed]

33. Fratta, P.; Birsa, N.; Tosolini, A.P.; Schiavo, G. Travelling Together: A Unifying Pathomechanism for ALS. Trends Neurosci. 2020, 43, 1-2. [CrossRef] [PubMed]

34. Liu, X.; Wu, C.; He, J.; Zhang, N.; Fan, D. Two rare variants of the ANXA11 gene identified in Chinese patients with amyotrophic lateral sclerosis. Neurobiol. Aging 2019, 74, 235.e9-235.e12. [CrossRef] [PubMed]

35. Smith, B.N.; Topp, S.D.; Fallini, C.; Shibata, H.; Chen, H.J.; Troakes, C.; King, A.; Ticozzi, N.; Kenna, K.P.; Soragia-Gkazi, A.; et al. Mutations in the vesicular trafficking protein annexin A11 are associated with amyotrophic lateral sclerosis. Sci. Transl. Med. 2017, 9. [CrossRef] [PubMed]

36. Tsai, P.C.; Liao, Y.C.; Jih, K.Y.; Soong, B.W.; Lin, K.P.; Lee, Y.C. Genetic analysis of ANXA11 variants in a Han Chinese cohort with amyotrophic lateral sclerosis in Taiwan. Neurobiol. Aging 2018, 72, 188.e1-188.e2. [CrossRef] [PubMed]

37. Zhang, K.; Liu, Q.; Liu, K.; Shen, D.; Tai, H.; Shu, S.; Ding, Q.; Fu, H.; Liu, S.; Wang, Z.; et al. ANXA11 mutations prevail in Chinese ALS patients with and without cognitive dementia. Neurol. Genet. 2018, 4, e237. [CrossRef]

38. Chomczynski, P.; Sacchi, N. Single-step method of RNA isolation by acid guanidinium thiocyanate-phenol-chloroform extraction. Anal. Biochem. 1987, 162, 156-159. [CrossRef]

39. Miles, A.J.; Wallace, B.A. CDtoolX, a downloadable software package for processing and analyses of circular dichroism spectroscopic data. Protein Sci. 2018, 27, 1717-1722. [CrossRef]

40. Blanchet, C.E.; Spilotros, A.; Schwemmer, F.; Graewert, M.A.; Kikhney, A.; Jeffries, C.M.; Franke, D.; Mark, D.; Zengerle, R.; Cipriani, F.; et al. Versatile sample environments and automation for biological solution X-ray scattering experiments at the P12 beamline (PETRA III, DESY). J. Appl. Crystallogr. 2015, 48, 431-443. [CrossRef]

41. Franke, D.; Petoukhov, M.V.; Konarev, P.V.; Panjkovich, A.; Tuukkanen, A.; Mertens, H.D.T.; Kikhney, A.G.; Hajizadeh, N.R.; Franklin, J.M.; Jeffries, C.M.; et al. ATSAS 2.8: A comprehensive data analysis suite for small-angle scattering from macromolecular solutions. J. Appl. Crystallogr. 2017, 50, 1212-1225. [CrossRef] [PubMed] 
42. Svergun, D.I. Determination of the regularization parameter in indirect-transform methods using perceptual criteria. J. Appl. Crystallogr. 1992, 25, 495-503. [CrossRef]

43. Svergun, D.; Barberato, C.; Koch, M.H.J. CRYSOL-A Program to Evaluate X-ray Solution Scattering of Biological Macromolecules from Atomic Coordinates. J. Appl. Crystallogr. 1995, 28, 768-773. [CrossRef]

44. Svergun, D.I.; Petoukhov, M.V.; Koch, M.H. Determination of domain structure of proteins from X-ray solution scattering. Biophys. J. 2001, 80, 2946-2953. [CrossRef]

45. Kozin, M.B.; Svergun, D.I. Automated matching of high-and low-resolution structural models. J. Appl. Crystallogr. 2001, 34, 33-41. [CrossRef]

46. Cianci, M.; Bourenkov, G.; Pompidor, G.; Karpics, I.; Kallio, J.; Bento, I.; Roessle, M.; Cipriani, F.; Fiedler, S.; Schneider, T.R. P13, the EMBL macromolecular crystallography beamline at the low-emittance PETRA III ring for high- and low-energy phasing with variable beam focusing. J. Synchrotron Radiat. 2017, 24, 323-332. [CrossRef] [PubMed]

47. Kabsch, W. XDS. Acta Crystallogr. D Biol. Crystallogr. 2010, 66, 125-132. [CrossRef]

48. McCoy, A.J.; Grosse-Kunstleve, R.W.; Adams, P.D.; Winn, M.D.; Storoni, L.C.; Read, R.J. Phaser crystallographic software. J. Appl. Crystallogr. 2007, 40, 658-674. [CrossRef]

49. Sutton, R.B.; Sprang, S.R. Three dimensional structure of annexin IV. In Annexins: Molecular Structure to Cellular Function; Seaton, B.A., Ed.; Landes Biosciences: Georgetown, TX, USA, 1996.

50. Afonine, P.V.; Grosse-Kunstleve, R.W.; Echols, N.; Headd, J.J.; Moriarty, N.W.; Mustyakimov, M.; Terwilliger, T.C.; Urzhumtsev, A.; Zwart, P.H.; Adams, P.D. Towards automated crystallographic structure refinement with phenix.refine. Acta Crystallogr. D Biol. Crystallogr. 2012, 68, 352-367. [CrossRef]

51. Emsley, P.; Lohkamp, B.; Scott, W.G.; Cowtan, K. Features and development of Coot. Acta Crystallogr. D Biol. Crystallogr. 2010, 66, 486-501. [CrossRef]

52. Davis, I.W.; Murray, L.W.; Richardson, J.S.; Richardson, D.C. MOLPROBITY: Structure validation and all-atom contact analysis for nucleic acids and their complexes. Nucleic Acids Res. 2004, 32, W615-W619. [CrossRef] [PubMed]

53. DeLano, W.L. Pymol: An open-source molecular graphics tool. CCP4 Newsl. Protein Crystallogr. 2002, 40, 82-92.

54. Unni, S.; Huang, Y.; Hanson, R.M.; Tobias, M.; Krishnan, S.; Li, W.W.; Nielsen, J.E.; Baker, N.A. Web servers and services for electrostatics calculations with APBS and PDB2PQR. J. Comput. Chem. 2011, 32, 1488-1491. [CrossRef] [PubMed]

55. Aukrust, I.; Evensen, L.; Hollås, H.; Berven, F.; Atkinson, R.A.; Travé, G.; Flatmark, T.; Vedeler, A. Engineering, biophysical characterisation and binding properties of a soluble mutant form of annexin A2 domain IV that adopts a partially folded conformation. J. Mol. Biol. 2006, 363, 469-481. [CrossRef]

56. Ecsédi, P.; Kiss, B.; Gógl, G.; Radnai, L.; Buday, L.; Koprivanacz, K.; Liliom, K.; Leveles, I.; Vértessy, B.; Jeszenői, N.; et al. Regulation of the Equilibrium between Closed and Open Conformations of Annexin A2 by N-Terminal Phosphorylation and S100A4-Binding. Structure 2017, 25, 1195-1207.e5. [CrossRef]

57. Bances, P.; Fernandez, M.R.; Rodriguez-Garcia, M.I.; Morgan, R.O.; Fernandez, M.P. Annexin A11 (ANXA11) gene structure as the progenitor of paralogous annexins and source of orthologous cDNA isoforms. Genomics 2000, 69, 95-103. [CrossRef]

58. Iglesias, J.M.; Morgan, R.O.; Jenkins, N.A.; Copeland, N.G.; Gilbert, D.J.; Fernandez, M.P. Comparative genetics and evolution of annexin A13 as the founder gene of vertebrate annexins. Mol. Biol. Evol. 2002, 19, 608-618. [CrossRef]

59. Fernandez, M.P.; Jenkins, N.A.; Gilbert, D.J.; Copeland, N.G.; Morgan, R.O. Sequence and Chromosomal Localization of Mouse Annexin XI. Genomics 1996, 37, 366-374. [CrossRef]

60. Hornbeck, P.V.; Chabra, I.; Kornhauser, J.M.; Skrzypek, E.; Zhang, B. PhosphoSite: A bioinformatics resource dedicated to physiological protein phosphorylation. Proteomics 2004, 4, 1551-1561. [CrossRef]

61. Kaetzel, M.A.; Mo, Y.D.; Mealy, T.R.; Campos, B.; Bergsma-Schutter, W.; Brisson, A.; Dedman, J.R.; Seaton, B.A. Phosphorylation mutants elucidate the mechanism of annexin IV-mediated membrane aggregation. Biochemistry 2001, 40, 4192-4199. [CrossRef]

62. Freye-Minks, C.; Kretsinger, R.H.; Creutz, C.E. Structural and dynamic changes in human annexin VI induced by a phosphorylation-mimicking mutation, T356D. Biochemistry 2003, 42, 620-630. [CrossRef] [PubMed] 
63. Chen, Z.; Mao, Y.; Yang, J.; Zhang, T.; Zhao, L.; Yu, K.; Zheng, M.; Jiang, H.; Yang, H. Characterizing the binding of annexin $\mathrm{V}$ to a lipid bilayer using molecular dynamics simulations. Proteins 2014, 82, 312-322. [CrossRef] [PubMed]

64. Hong, S.; Na, S.; Kim, O.H.; Jeong, S.; Oh, B.C.; Ha, N.C. High-resolution structures of annexin A5 in a two-dimensional array. J. Struct. Biol. 2020, 209, 107401. [CrossRef] [PubMed]

65. Lin, Y.C.; Chipot, C.; Scheuring, S. Annexin-V stabilizes membrane defects by inducing lipid phase transition. Nat. Commun. 2020, 11, 230. [CrossRef]

66. Mo, Y.; Campos, B.; Mealy, T.R.; Commodore, L.; Head, J.F.; Dedman, J.R.; Seaton, B.A. Interfacial basic cluster in annexin $\mathrm{V}$ couples phospholipid binding and trimer formation on membrane surfaces. J. Biol. Chem. 2003, 278, 2437-2443. [CrossRef]

67. Concha, N.O.; Head, J.F.; Kaetzel, M.A.; Dedman, J.R.; Seaton, B.A. Annexin V forms calcium-dependent trimeric units on phospholipid vesicles. FEBS Lett. 1992, 314, 159-162. [CrossRef]

68. Crosby, K.C.; Postma, M.; Hink, M.A.; Zeelenberg, C.H.; Adjobo-Hermans, M.J.; Gadella, T.W. Quantitative analysis of self-association and mobility of annexin A4 at the plasma membrane. Biophys. J. 2013, 104, 1875-1885. [CrossRef]

69. Ravanat, C.; Torbet, J.; Freyssinet, J.M. A neutron solution scattering study of the structure of annexin-V and its binding to lipid vesicles. J. Mol. Biol. 1992, 226, 1271-1278. [CrossRef]

70. Aukrust, I.; Hollås, H.; Strand, E.; Evensen, L.; Travé, G.; Flatmark, T.; Vedeler, A. The mRNA-binding site of annexin A2 resides in helices C-D of its domain IV. J. Mol. Biol. 2007, 368, 1367-1378. [CrossRef]

71. Solbak, S.M.Ø.; Abdurakhmanov, E.; Vedeler, A.; Danielson, U.H. Characterization of interactions between hepatitis C virus NS5B polymerase, annexin A2 and RNA-Effects on NS5B catalysis and allosteric inhibition. Virol. J. 2017, 14, 236. [CrossRef]

72. Pandurangan, A.P.; Ochoa-Montaño, B.; Ascher, D.B.; Blundell, T.L. SDM: A server for predicting effects of mutations on protein stability. Nucleic Acids Res. 2017, 45, W229-W235. [CrossRef] [PubMed]

73. Gomes, E.; Shorter, J. The molecular language of membraneless organelles. J. Biol. Chem. 2019, 294, 7115-7127. [CrossRef]

74. Vernon, R.M.; Chong, P.A.; Tsang, B.; Kim, T.H.; Bah, A.; Farber, P.; Lin, H.; Forman-Kay, J.D. Pi-Pi contacts are an overlooked protein feature relevant to phase separation. Elife 2018, 7. [CrossRef] [PubMed]

75. Misaki, Y.; Van Venrooij, W.J.; Pruijn, G.J. Prevalence and characteristics of anti-56K/annexin XI autoantibodies in systemic autoimmune diseases. J. Rheumatol. 1995, 22, 97-102. [PubMed]

76. Sjolin, C.; Movitz, C.; Lundqvist, H.; Dahlgren, C. Translocation of annexin XI to neutrophil subcellular organelles. Biochim. Biophys. Acta 1997, 1326, 149-156. [CrossRef]

77. Li, H.R.; Chiang, W.C.; Chou, P.C.; Wang, W.J.; Huang, J.R. TAR DNA-binding protein 43 (TDP-43) liquid-liquid phase separation is mediated by just a few aromatic residues. J. Biol. Chem. 2018, 293, 6090-6098. [CrossRef]

78. Nguyen, H.P.; Van Broeckhoven, C.; van der Zee, J. ALS Genes in the Genomic Era and their Implications for FTD. Trends Genet. 2018, 34, 404-423. [CrossRef]

79. Wei, Q.; Chen, X.; Chen, Y.; Ou, R.; Cao, B.; Hou, Y.; Zhang, L.; Shang, H.F. Unique characteristics of the genetics epidemiology of amyotrophic lateral sclerosis in China. Sci. China Life Sci. 2019, 62, 517-525. [CrossRef]

(C) 2020 by the authors. Licensee MDPI, Basel, Switzerland. This article is an open access article distributed under the terms and conditions of the Creative Commons Attribution (CC BY) license (http://creativecommons.org/licenses/by/4.0/). 